controlled for in the multivariate analysis. Furthermore, the suggested risk factors occurring later in life, such as psychological mechanisms and drug availability and exposition, cannot explain the demonstrated associations between administration of drugs during the perinatal period and subsequent addiction in offspring. Also, genetic and socioeconomic factors were largely controlled for by matching addicts with their own siblings.

In conclusion, effective pain relief is sometimes an important factor for a successful outcome of delivery, as well as for the ability of the mother to accept and care for the child in the future. At present, when considering the choice of analgesic method immediate risks and benefits are mainly taken into account. When depressant or sedative drugs are used their possible long term effects due to imprinting also seem to be important. From this point of view, analgesic methods not associated with passage of substantial amounts of drugs across the placenta are preferable. Our results are compatible with the imprinting hypothesis, and we have not found reason to reject it. This study and the previous study on amphetamine addiction need to be repeated by other investigators. We consider it essential that siblings are then used as controls as we have some evidence of family related risk factors, which we shall publish elsewhere; to control for such factors it is mandatory to match probands with siblings.

This study was approved by the ethics committees of the Karolinska Institute and Uppsala University and was supported by the Expressen Prenatal Research Foundation. We thank Professor Lars Gunne, Ulleråker University Hospital, Uppsala, and Professor Lars Terenius, Karolinska Institute, for their views on the effects of nitrous oxide and their helpful suggestions.

1 Lorenz K. Der Kumpan in der Umwelt des Vogels. Fournal of (Omuthology $1935 ; 83: 137-213,289-413$

2 Horn $G$. Neural mechanisms of learning: an analysis of imprinting in the domestic chick. Proc R Soc Lond [Biol] 1981;213:101-37.

3 Salzen EA. Imprinting in birds and primates. Behaviour 1967:28:232-54

Salk L. Thoughts on the concept of imprinting and its place in early humen development. Canadian Psychiatric Association fournal 1966;11:295-305.

decopich Peobson B, Eklund G, Hamberger L, Linnarsson D, Sedvall G, Valverius M Perinatal origin of adult self-destructive behavior. Acta Psychiatr Scand
1987;76:364-71.

6 Jacobson B, Nyberg K, Eklund G, Bygdeman M, Rydberg U. Obstetric pain medication and eventual adult amphetamine addiction in offspring. Acta Obstet (ivnnecol Scand 1988;67:677-82.

7 Breslow NE, Day NE. Statistical methods in cancer research. Lyons: World Health Organisation, 1980:248-79. (International Agency for Research on Cancer Scientific Publication No 32, vol 1.)

8 Belfrage P, Boréus LO, Hartvig P, Irestedt L, Raabe N. Neonatal depression after obstetrical analgesia with pethidine. Acta Obstet Gynecol Scand $1981 ; 60: 43-9$

9 Hynes MD, Berkowitz BA. Catecholamine mechanisms in the stimulation of mouse locomotor activity by nitrous oxide and morphine. Eur 7 Pharmacol 1983;90:109-14.

10 Jönsson LE, Gunne LM, Änggard E. Effects of alphamethyltyrosine in amphetamine-dependent subjects. Pharmacologica Clinica 1969:2:27-9.

11 Lagercrantz H, Slotkin TA. The "stress" of being born. Sci Am 1986;254: $92-102$

12 Kovach JK. Effects of autonomic drugs on imprinting. Fournal of Comparative and Physiological Psychology 1964:57:183-7.

13 Brazelton TB. Effect of perinatal drugs on the behavior of the neonate. Am F Psychiatry 1970;126:1261-6.

14 James H. Imprinting with visual flicker: effects of testosterone cyclopentylpropionate. Animal Behaviour 1962;10:341-6.

(Accepted 31 August 1990)

\title{
Can prepregnancy care of diabetic women reduce the risk of abnormal babies?
}

\author{
Judith M Steel, Frank D Johnstone, David A Hepburn, Alistair F Smith
}

Royal Infirmary of Edinburgh, Edinburgh EH3 9YW

Judith M Steel, FRCPED, associate specialist, diabetic department

David A Hepburn, MRCP, registrar, diabetic department Alistair F Smith, FRCPATH senior lecturer, department of clinical chemistry

Department of Obstetrics, University of Edinburgh,

Edinburgh

Frank D Johnstone, FRCOG, senior lecturer

Correspondence to:

Dr Steel.

Br Med f 1990;301:1070-4

\section{Abstract}

Objective - To see whether a prepregnancy clinic for diabetic women can achieve tight glycaemic control in early pregnancy and so reduce the high incidence of major congenital malformation that occurs in the infants of these women.

Design-An analysis of diabetic control in early pregnancy including a record of severe hypoglycaemic episodes in relation to the occurrence of major congenital malformation among the infants.

Setting-A diabetic clinic and a combined diabetic and antenatal clinic of a teaching hospital.

Patients-143 Insulin dependent women attending a prepregnancy clinic and 96 insulin dependent women managed over the same period who had not received specific prepregnancy care.

Main outcome measure-The incidence of major congenital malformation.

Results-Compared with the women who were not given specific prepregnancy care the group who attended the prepregnancy clinic had a lower haemoglobin $A_{I}$ concentration in the first trimester $(8.4 \% v$ $10.5 \%)$, a higher incidence of hypoglycaemia in early pregnancy (38/143 women $v 8 / 96$ ), and fewer infants with congenital abnormalities $(2 / 143 v 10 / 96$; relative risk among women not given specific prepregnancy care $7 \cdot 4(95 \%$ confidence interval 1.7 to $33 \cdot 2)$ ).

Conclusion-Tight control of the maternal blood glucose concentration in the early weeks of pregnancy can be achieved by the prepregnancy clinic approach and is associated with a highly significant reduction in the risk of serious congenital abnormalities in the offspring. Hypoglycaemic episodes do not seem to lead to fetal malformation even when they occur during the period of organogenesis.

\section{Introduction}

There is a high incidence of congenital malformation in infants of diabetic mothers. ${ }^{1.3}$ Both in rats ${ }^{45}$ and in humans ${ }^{6-9}$ the higher are the maternal blood glucose concentrations over the period of organogenesis the greater is the chance of an abnormality in the offspring. In 1976 we started a prepregnancy clinic for diabetic women. The aims of the clinic are manifold, ${ }^{10-12}$ but the most important has become the optimisation of diabetic control over the period of conception in an attempt to reduce the incidence of major congenital abnormalities. Tightening control in early pregnancy inevitably increases the frequency of hypoglycaemia. Recent work with rats has shown that hypoglycaemia at a critical stage of development - namely, equivalent to days 32-40 in humans (18-26 days after ovulation)can cause congenital abnormalities. ${ }^{13-16}$ Hence the desirability of reducing blood glucose concentrations in early pregnancy has been questioned. ${ }^{16}$

This paper reports the first 14 years' experience of our prepregnancy clinic, comparing results in women who attended the clinic with those in a group of women who did not.

\section{Patients and methods}

The prepregnancy clinic is advertised to insulin dependent diabetic women by personal contact, posters, and articles in newsletters. Contraception 
and future pregnancy are discussed with most of the young women who attend our clinic, but patients are registered as coming to the prepregnancy clinic when they declare their intent to have a pregnancy and come with their partner to the clinic run jointly by a physician and an obstetrician. At the initial visit a medical, obstetric, and gynaecological history is taken. Diabetic complications are assessed with particular reference to retinopathy, renal function, blood pressure, ischaemic heart disease, and autonomic neuropathy. Some patients have received laser treatment for retinopathy before pregnancy and a few have been advised against pregnancy. ${ }^{17}$ The importance of tight control throughout pregnancy is explained. Our programme of management of diabetic pregnancy is discussed and written information provided. Diabetic control is optimised, intensive dietetic advice given, and the insulin regimen changed or adjusted to achieve preprandial blood glucose concentrations as near as possible to $4 \mathrm{mmol} / \mathrm{l}$. The partner is taught how to treat hypoglycaemia orally and with glucagon. The importance of testing for ketones and the management of vomiting are discussed. Immunity to rubella and thyroid function are checked. Strong advice is given against smoking.

In the early years haemoglobin $A_{1}$ measurements were not available. After they became available the general level of control in our diabetic clinic improved, and we now aim at achieving a haemoglobin $A_{1}$ concentration within or very close to the normal range. Once glycaemic control has been optimised couples stop contraception. When the woman reports having not bled for six weeks since her last menstrual period a pregnancy test is done. If the result is positive she is booked into the combined antenatal clinic.

Over the first few years the proportion of our own patients attending the clinic gradually increased. After 1983 it fluctuated from year to year between $75 \%$ and $83 \%$. Those not enrolled in the prepregnancy clinic included 58 patients from our own clinic who either did not know about the special clinic or knew but did not wish or could not organise themselves to come. A further nine patients moved to Edinburgh when they were already pregnant, 13 were referred from clinics with no obstetric centre, and seven were sent to us as a tertiary referral centre because of diabetic or obstetric problems.

\section{PRESENT SERIES}

We compared diabetic control in early pregnancy and the incidence of major congenital abnormalities in

TABLE I-Simplified White's classification of insulin dependent pregnant diabetic mothers

\begin{tabular}{|c|c|c|c|c|}
\hline $\begin{array}{l}\text { White's } \\
\text { classification }\end{array}$ & $\begin{array}{c}\text { Age at onset } \\
\text { of diabetes } \\
\text { (years) }\end{array}$ & & $\begin{array}{c}\text { Duration of } \\
\text { diabetes } \\
\text { (years) }\end{array}$ & Complications \\
\hline $\begin{array}{l}\text { B } \\
\text { C } \\
\text { D } \\
\text { F } \\
\text { R }\end{array}$ & $\begin{array}{l}\geqslant 20 \\
10-19 \\
<10\end{array}$ & $\begin{array}{l}\text { and } \\
\text { or } \\
\text { or }\end{array}$ & $\begin{array}{c}<10 \\
10-19 \\
\geqslant 20\end{array}$ & $\begin{array}{l}\text { Absent } \\
\text { Absent } \\
\text { Background retinopathy } \\
\text { Nephropathy } \\
\text { Proliferative retinopathy }\end{array}$ \\
\hline
\end{tabular}

TABLE II -Clinical characteristics of attenders ( $n=143)$ and non-attenders $(n=96)$ at prepregnancy clinic for diabetic women. [Figures in square brackets are numbers of women for whom data were available]

\begin{tabular}{lccc}
\hline & Attenders & Non-attenders & p Value \\
\hline Mean age (years) (SD) & $27 \cdot 5(3 \cdot 9)[\mathrm{n}=143]$ & $25 \cdot 2(4 \cdot 6)[\mathrm{n}=96]$ & $<0 \cdot 01^{\star}$ \\
Mean weight at booking $(\mathrm{kg})(\mathrm{SD})$ & $63 \cdot 5(9 \cdot 0)[\mathrm{n}=137]$ & $63 \cdot 9(10 \cdot 8)[\mathrm{n}=92]$ & $\mathrm{NS}^{\star}$ \\
No $(\%)$ married or in stable relationship & $135(94)[\mathrm{n}=143]$ & $72(75)[\mathrm{n}=96]$ & $<0 \cdot 001 \dagger$ \\
No $(\%)$ primigravid & $71(50)[\mathrm{n}=143]$ & $58(60)[\mathrm{n}=96]$ & $\mathrm{NS} \dagger$ \\
No $(\%)$ smoking & $33(24)[\mathrm{n}=137]$ & $41(45)[\mathrm{n}=92]$ & $<0 \cdot 005 \dagger$ \\
No(\%) in social classes I-IIIa & $52(38)[\mathrm{n}=137]$ & $27(29)[\mathrm{n}=92]$ \\
No(\%) in social classes IIIb-V & $85(62)[\mathrm{n}=137]$ & $65(71)[\mathrm{n}=92]\}$ & $\mathrm{NS} \dagger$ \\
\hline
\end{tabular}

*Independent $t$ test.

t $\chi^{2}$ Test. a consecutive series of 143 insulin dependent diabetic women seen since 1976 who attended our prepregnancy clinic and 96 women who did not attend. We included all patients with insulin dependent diabetes before conception delivered in our hospital whose pregnancies continued beyond 20 weeks as well as those who had a therapeutic abortion because of a severe congenital abnormality. One patient was taking anticonvulsants and one steroids. No other patient was taking a drug known to be teratogenic and none had a first degree relative with a heritable disorder known to cause major malformation. All patients were categorised in terms of the duration of diabetes and severity of complications according to White's classification ${ }^{18}$ (table I). The two groups were compared for age, weight, parity, marital state, social class (registrar general's classification), and smoking.

Haemoglobin $A_{1}$ measurements-From 1979 haemoglobin $\mathrm{A}_{1}$ measurements were recorded at the time of first attendance at the prepregnancy clinic, at booking, and every two weeks during the antenatal period. Initially the method of Kynoch and Lehmann ${ }^{19}$ as modified by Fraser et $a l^{20}$ was used and later an electrophoretic method with the same normal range $(5 \cdot 9-8 \cdot 0 \%) .21$

Hypoglycaemia - All patients were questioned about episodes of severe hypoglycaemia at their first antenatal clinic visit. A severe episode was defined as hypoglycaemia rendering self treatment impossible and requiring someone else to give oral glucose, glucagon, or intravenous glucose. Before 1988 the exact dates of severe hypoglycaemic incidents were not always recorded. All episodes occurring in the first nine weeks of pregnancy were analysed (dates being taken from the first ultrasound scan). We did a specific prospective study of severe hypoglycaemia occurring between days 32 and 40 in the last 25 patients.

Congenital abnormalities - All babies were examined by an experienced paediatrician and all except the most recently delivered followed up for at least a year. A major congenital malformation was one causing death or serious handicap or requiring major surgical correction.

Statistical methods-Calculations were performed with the SPSS/PC version 3.0 statistical package on an IBM PS/2. Differences between women who had attended the prepregnancy clinic and those who had not-for example, in relation to the occurrence of hypoglycaemia and the incidence of abnormal babies were assessed by the $\chi^{2}$ test with Yates's correction. The paired or unpaired $t$ test, as appropriate, was used to compare continuous data. $p$ Values of 0.05 or less were accepted as significant.

\section{Results}

Characteristics of patients - Table II gives the clinical characteristics of women in the two groups. Nonattenders at the prepregnancy clinic were significantly younger, less likely to be married, and much more likely to smoke. Non-attenders were also more likely to be primigravid and were of slightly lower social class, but these differences were not significant. There was no significant difference in the distribution of White's classification between the two groups (table III). Only two truly unplanned pregnancies had occurred since 1981. Most of the pregnancies initially recorded as unplanned were, in fact, carefully planned by the mother.

Haemoglobin $A_{1}$ concentrations - Table IV gives the summary data for haemoglobin $A_{1}$ concentrations at first attendance, booking, and during pregnancy. The mean value for haemoglobin $A_{1}$ during the first trimester was significantly lower among attenders at the prepregnancy clinic $(8.4 \%)$ than among the non 
TABLE III-Distribution of White's classification of duration of diabetes and severity of complications among attenders and nonattenders at prepregnancy clinic for diabetic women

\begin{tabular}{lccccc}
\hline & \multicolumn{5}{c}{ White's classification } \\
\cline { 3 - 6 } & B & C & D & R/F & Total \\
\hline $\begin{array}{l}\text { No(\%) of attenders } \\
\text { No(\%) of } \\
\text { non-attenders }\end{array}$ & $27(19)$ & $37(26)$ & $62(43)$ & $17(12)$ & $143(100)$ \\
\hline
\end{tabular}

TABLE IV-Mean (SD) haemoglobin $A_{I}$ concentrations before and during pregnancy among attenders and non-attenders at prepregnancy clinic for diabetic women. [Figures in square brackets are numbers of women for whom data were available]

\begin{tabular}{lrr}
\hline & \multicolumn{2}{c}{ Haemoglobin $A_{1}(\%)$} \\
\cline { 2 - 3 } & \multicolumn{1}{c}{ Attenders } & Non-attenders \\
\hline First attendance & $11 \cdot 9(2 \cdot 4)[n=118]$ & - \\
Booking & $8 \cdot 9(1 \cdot 5)[n=135]$ & $10 \cdot 9(2 \cdot 2)[n=69]$ \\
First trimester & $8 \cdot 4(1 \cdot 3)[n=135]$ & $10 \cdot 5(2 \cdot 0)[n=50]$ \\
Second trimester & $7 \cdot 8(1 \cdot 0)[n=134]$ & $8 \cdot 9(1 \cdot 6)[n=64]$ \\
Third trimester & $7 \cdot 6(1 \cdot 0)[n=134]$ & $8 \cdot 1(1 \cdot 1)[n=67]$ \\
\hline
\end{tabular}

attenders $(10.5 \%)$ (independent $t$ test: $\mathrm{p}<0.0001$ ). Among the 118 attenders for whom data at the first attendance were available the haemoglobin $A_{1}$ concentrations fell by an average of $3 \cdot 2 \%$ from $11.9 \%$ at first attendance at the clinic to $8.7 \%$ at booking (paired $t$ test: $\mathrm{p}<0 \cdot 0001)$.

Hypoglycaemia was significantly more common in all patients who had attended the prepregnancy clinic than in non-attenders $\left(38 / 143\right.$ women $v 8 / 96 ; \chi^{2}=11 \cdot 1$, $\mathrm{p}<0.001)$. One out of 12 mothers who had abnormal babies had experienced hypoglycaemia during the first nine weeks. The other 45 patients, who had severe hypoglycaemia in the first nine weeks, had normal babies. Of the last 25 patients in the series, two had severe hypoglycaemia and 11 had mild episodes between days 32 and 40 ; the only woman who delivered a baby with a congenital abnormality, however, had not had hypoglycaemia over that period.

Congenital malformations-There were 12 infants with major congenital malformations. Table $\mathrm{V}$ gives the details. The malformations were significantly more common in babies born to patients who had not attended the prepregnancy clinic $(10 / 96 ; 10.4 \%)$ than in babies of mothers who had attended $(2 / 143 ; 1.4 \%)$ $\left(\chi^{2}=8 \cdot 0, p<0 \cdot 005 ;\right.$ relative risk among non-attenders $7 \cdot 4(95 \%$ confidence interval $1 \cdot 7$ to $33 \cdot 2))$. All patients taking anticonvulsants and steroids had normal babies, as did the seven patients referred because of diabetic or obstetric problems. Only one patient who moved to
Edinburgh when already pregnant had an abnormal baby. All the other congenital malformations occurred in our own clinic population.

\section{Discussion}

Our two groups were not randomised. Patients attending the prepregnancy clinic selected themselves. They were motivated towards pregnancy, but in most cases their diabetes was not well controlled initially. Their mean haemoglobin $A_{1}$ concentration of $11.9 \%$ was similar to that in a cohort of young insulin dependent diabetic patients attending our clinic who were being followed up..$^{22}$ There was a highly significant improvement in control between the time of first attendance at the prepregnancy clinic and booking in pregnancy. As expected, women not attending the prepregnancy clinic were younger and less likely to be married, but the effect, if any, that this would be expected to have on congenital abnormalities is very small. The age range, marital state, and parity of those who had abnormal babies did not suggest that they were a particularly high risk group on these grounds.

We expected that there would be significantly fewer smokers among women who had attended the prepregnancy clinic as one of the aims of the clinic is to persuade patients to stop smoking. We are disappointed that the clinic has not been more successful in this respect, and the overall incidence of smoking in diabetic patients is similar to that among all patients attending the antenatal clinic at our hospital. Though smoking is related to poor outcome of pregnancy, it has never specifically been implicated in congenital abnormalities.

Patients who did not attend the prepregnancy clinic were significantly less well controlled than attenders at booking. Nevertheless, they were better than the attenders when first seen because some had already tightened control knowing that they were pregnant.

All our patients attending the prepregnancy clinic were seen very early in pregnancy, most at about six weeks' gestation. Nineteen of the non-attenders at the prepregnancy clinic failed to attend the antenatal clinic in the first trimester. Fourteen of these patients were referred from other centres already pregnant. In the other five we have circumstantial evidence based on haemoglobin $\mathrm{A}_{1}$ concentrations recorded before pregnancy and in the second trimester that they were poorly controlled. This group included two patients who had abnormal babies. Both mothers admitted to omitting insulin frequently in early pregnancy. It is inevitable in any such study that some unreliable,

TABLE V-Details of cases resulting in major congenital abnormalities in infants

\begin{tabular}{|c|c|c|c|c|c|c|c|c|c|c|}
\hline Case No & $\begin{array}{l}\text { Attended } \\
\text { pre- } \\
\text { pregnancy } \\
\text { clinic }\end{array}$ & $\begin{array}{c}\text { Haemoglobin } \\
\mathrm{A}_{1} \text { in first } \\
\text { trimester }(\%)\end{array}$ & $\begin{array}{c}\text { Severe } \\
\text { hypoglycaemia } \\
\text { in first } \\
\text { nine weeks }\end{array}$ & $\begin{array}{c}\text { Maternal } \\
\text { age (years) }\end{array}$ & $\begin{array}{l}\text { White's } \\
\text { classification }\end{array}$ & Marital state & Parity & Smoking & Social class & Congenital defect in infant \\
\hline 1 & No & Before assay & No & 27 & $\mathrm{R}$ & $\begin{array}{l}\text { Married or in stable } \\
\text { relationship }\end{array}$ & 1 & Yes & II & Encephalocele \\
\hline 2 & No & $\begin{array}{l}\text { Too late, omitted } \\
\text { insulin }\end{array}$ & No & 24 & $\mathrm{C}$ & $\begin{array}{l}\text { Married or in stable } \\
\text { relationship }\end{array}$ & 2 & No & IV & Anencephaly \\
\hline 3 & No & $\begin{array}{l}\text { Too late, omitted } \\
\text { insulin }\end{array}$ & No & 27 & $\mathrm{R} / \mathrm{F}$ & $\begin{array}{l}\text { Married or in stable } \\
\text { relationship }\end{array}$ & 0 & Yes & IIIa & Sacral hypoplasia, urinary incontinence \\
\hline 4 & No & Too late & No & 18 & $\mathrm{C}$ & Single & 0 & No & II & Microcephaly \\
\hline 5 & No & $13 \cdot 4$ & No & 21 & $\mathrm{C}$ & $\begin{array}{l}\text { Married or in stable } \\
\text { relationship }\end{array}$ & 0 & Yes & $\mathrm{V}$ & Sirenomelia, renal agenesis \\
\hline 6 & No & $11 \cdot 6$ & No & 24 & $\mathrm{D}$ & $\begin{array}{l}\text { Married or in stable } \\
\text { relationship }\end{array}$ & 1 & No & IV & $\begin{array}{l}\text { Kyphoscoliosis requiring early fusion, } \\
\text { partial deafness }\end{array}$ \\
\hline 7 & No & $11 \cdot 4$ & Yes & 23 & $\mathrm{C}$ & $\begin{array}{l}\text { Married or in stable } \\
\text { relationship }\end{array}$ & 1 & Yes & IIIa & Monomelia, renal agenesis \\
\hline 8 & No & $13 \cdot 8$ & No & 25 & C & $\begin{array}{l}\text { Married or in stable } \\
\text { relationship }\end{array}$ & 1 & No & IIIb & $\begin{array}{l}\text { Kyphoscoliosis requiring early fusion, } \\
\text { partial deafness }\end{array}$ \\
\hline 9 & No & $13 \cdot 7$ & No & 34 & B & $\begin{array}{l}\text { Married or in stable } \\
\text { relationship }\end{array}$ & 1 & Yes & IIIb & $\begin{array}{l}\text { Single ventricle mitral atresia, aortic arch } \\
\text { hypoplasia }\end{array}$ \\
\hline 10 & No & $14 \cdot 9$ & No & 23 & $\mathrm{C}$ & $\begin{array}{l}\text { Married or in stable } \\
\text { relationship }\end{array}$ & 1 & Yes & V & Fallot's tetralogy, abnormal venous drainage \\
\hline 11 & Yes & $9 \cdot 5$ & No & 35 & $\mathrm{D}$ & $\begin{array}{l}\text { Married or in stable } \\
\text { relationship }\end{array}$ & 1 & No & IIIa & Transposition of great vessels \\
\hline 12 & Yes & $8 \cdot 8$ & No & 25 & $\mathrm{D}$ & $\begin{array}{l}\text { Married or in stable } \\
\text { relationship }\end{array}$ & 1 & No & IIIb & Anencephaly \\
\hline
\end{tabular}


poorly controlled patients will present late, and we are now concentrating on these patients. Patients who did not attend the prepregnancy clinic but who did have their haemoglobin $A_{1}$ concentration measured in early pregnancy and had abnormal babies were all very poorly controlled (mean haemoglobin $\mathrm{A}_{1}$ concentration $13 \cdot 1 \%$ ). Accurate figures on the overall population incidence of major congenital malformation were not available, but most authorities consider that "significant" congenital malformations are present in $2-3 \%$ of liveborn infants. ${ }^{23}$ The two well controlled patients attending the prepregnancy clinic who had abnormal babies might therefore reflect the background frequency of congenital abnormalities in the nondiabetic population. Alternatively they may suggest that the haemoglobin $A_{1}$ concentration should be reduced still further or that fluctuations in concentrations of glucose or other metabolites are important. ${ }^{24}$

Studies of the effects of hypoglycaemia on rat embryos initially used long periods of exposure..$^{13-15}$ Akazawa et al recently exposed the embryos to a hypoglycaemic culture medium for one hour. ${ }^{16}$ Even this is equivalent to over six hours in humans. So far there have been no reports suggesting that hypoglycaemia causes congenital abnormalities in humans, although few studies have looked specifically at this problem. Studies of hypoglycaemic episodes in diabetic pregnancy have found no evidence that hypoglycaemia can cause congenital abnormalities, but the episodes have not been related to exact gestational dates. ${ }^{25-27}$ Mills $e t a l^{28}$ in their multicentre prospective study of diabetic control and congenital malformations found no difference in congenital malformations $\mathrm{s}^{29}$ arising between weeks 5 and 12 in patients who had or had not experienced episodes of presumed hypoglycaemia.

Asking patients about hypoglycaemic episodes occurring a few weeks earlier is not reliable and probably underestimates the incidence. It seems unlikely, however, that many patients will forget or fail to report severe episodes requiring outside help if they are asked specific questions. It is noteworthy that there were fewer congenital abnormalities in our prepregnancy clinic group despite an increased incidence of hypoglycaemia in the first nine weeks. The implications of this are supported by more detailed analysis of the last 25 patients in the series when hypoglycaemia was studied prospectively. Neither the two patients who had severe episodes nor the 11 who had mild episodes between days 32 and 40 had abnormal babies whereas the one patient who did have an abnormal baby had experienced no hypoglycaemia over that period. Larger numbers are needed to clarify the relation of hypoglycaemia to malformation in humans but the evidence so far is reassuring. We are, however, concerned about the danger of severe hypoglycaemia to the mothers, some of whom may have reduced warning sensations during pregnancy. Most of the severe episodes were successfully treated at home by relatives giving glucagon. Nevertheless, we have recorded a considerable number of grand mal seizures, five episodes of cerebral oedema, two road traffic accidents, and a comminuted fracture of the tibia and fibula, all attributable to hypoglycaemia in tightly controlled pregnant diabetic patients.

The only centre reporting a significant reduction in the incidence of major abnormalities as a result of prepregnancy care is a department in Karlsburg, East Germany. ${ }^{3031}$ Fuhrmann et al have published their experience from 1977 to 1981 and from 1981 to 1983. Over the whole seven years they had only two congenital malformations in 185 insulin dependent diabetic patients attending their prepregnancy clinic $(1 \cdot 1 \%)$ compared with 31 in 473 patients not attending $(6 \cdot 6 \%)$. Their practice is very different from that in the West. Patients receiving prepregnancy care were admitted to hospital every three months up to conception, admitted again as soon as the basal body temperature had been raised for more than 16 days, and admitted for further periods during pregnancy. Numerous blood glucose measurements were recorded but the haemoglobin $A_{1}$ concentration was not measured and hypoglycaemia was not reported.

Among our local diabetic population awareness of the importance of control before conception has increased substantially since our prepregnancy service began. Though we still need to concentrate on our less reliable patients, we are encouraged that over the years there has been a trend towards much earlier booking for antenatal care (even among patients not formally coming through the clinic), and we have noted that these patients have often improved their own control. Some of our least compliant patients have come with records of blood tests for the first time in years. ${ }^{17}$ Our patients are managed mainly as outpatients. Our prepregnancy clinic patients present very early in pregnancy, are highly motivated, and are well educated. Although there is a bias in selection, we think that improved control in early pregnancy-although associated with an increased incidence of hypoglycaemia - is likely to be an important factor in explaining the significantly lower incidence of major congenital abnormalities in patients attending our prepregnancy clinic. This has obvious and important implications for the organisation of medical and obstetric services available to growing numbers of young diabetic women in the United Kingdom and elsewhere.

We thank Novo-Nordisk for financial help with the analysis.

1 Molsted-Pedersen L, Tygstrup I, Pedersen J. Congenital malformations in newborn infants of diabetic women. Lancet 1964;i:1124-6.

2 Soler NG, Walsh CH, Malins JM. Congenital malformation in infants of diabetic mothers. Qf Med 1976;45:303-13.

3 Glasgow ACA, Harley JMG, Montgomery DAD. Congenital malformations in infants of diabetic mothers. Ulster Med f 1979;48:109-17.

4 Deuchar E. Experimental evidence relating fetal anomalies to diabetes. In Sutherland HW, Stowers JM, eds. Carbohydrate metabolism in pregnancy and the newborn. Berlin: Springer Verlag, 1978:247-63.

5 Baker L, Egler J, Kein S, Goldman AS. Meticulous control of diabetes during organogenesis prevents congenital lumbo-sacral defects in rats. Diabetes 1981;30:955-9.

6 Leslie RDG, John PN, Pyke DA, White JM. Haemoglobin Al in diabetic pregnancy. Lancet 1978;ii:958-9.

7 Miller E, Hare JW, Cloherty JP. Elevated maternal hemoglobin Al in early pregnancy and major congenital anomalies in infants of diabetic mothers. pregnancy and major congenital

8 Ylinen K, Rawo K, Teramo K. Haemoglobin Alc predicts the prenatal outcome in insulin dependent diabetic pregnancies in patients with diabetes. outcome in insulin dependent diabe

9 Stubbs SM, Doddridge MC, John PN, Steel JM, Wright AD. Haemoglobin Al and congenital malformation. Diabetic Med 1987;4:156-9.

10 Steel JM, Parboosingh J, Cole RA, Duncan LJP. Pre-pregnancy counselling, a logical prelude to the management of the pregnant diabetic. Diabetes Care 1980;3:371-3.

11 Steel JM, Johnstone FD, Smith AF, Duncan LJP. Five years' experience of pre-pregnancy clinic for insulin-dependent diabetics. Br Med $\mathcal{7}$ 1982;285 353-6.

12 Steel JM, Johnstone FD, Smith AF, Duncan LJP. The pre-pregnancy clinic approach. In: Sutherland HW, Stowers JM, eds. Carbohydrate metabolism in pregnancy and the newborn. London: Churchill Livingstone, 1984:75-86.

13 Buchanan TA, Schemmer JK, Freinkel N. Embryotoxic effects of brief maternal insulin-hypoglycemia during organogenesis in the rat. $\mathcal{F}$ Clin Invest 1986;78:643-9.

14 Akazawa S, Akazawa $M$, Hashimoto $M$, et al. Effects of hypoglycaemia on early embryogenesis in rat embryo organ culture. Diabetologia 1987;30: 91-6.

15 Ellington SKL. Development of rat embryos cultured on glucose-deficient media. Diabetes 1987;36:1372-8

16 Akazawa M, Akazawa S, Hashimoto $M$, et al. Effects of brief exposure of insulin induced hypoglycemic serum during organogenesis in rat embryo culture. Diabetes 1989;38:1573-8.

17 Steel JM, Johnstone FD, Smith AF. Pre-pregnancy preparation. In: Sutherland HW, Stowers JM, Pearson DWM, eds. Carbohydrate metabolism in pregnancy and the newborn IV. Berlin: Springer Verlag, 1989:129-39.

18 White P. Pregnancy and diabetes. In: Marble A, White P, Bradley R, Krall I, eds. Joslins' diabetes mellitus. Philadelphia: Lea and Febiger, 1971:595-7.

19 Kynoch PAM, Lehmann H. Rapid estimation of glycosylated haemoglobin for routine purposes. Lancet 1977;ii:16.

20 Fraser DM, Smith AF, Gray RS, et al. Glycosylated haemoglobin concentrations in newly diagnosed diabetics before and during treatment. $\mathrm{Br}$ Med $\mathcal{f}$ 1979:i:979-81.

21 Read A, Tibi L, Smith AF. Assessment of a simple electrophoretic method for measuring HbAl. Clin Chem Acta 1980;108:487-91. 
22 Young RJ, Macintyre CCA, Martyn CN, et al. Progression of sub-clinical polvneuropathy in voung patients with type 1 diabetes. Associations with

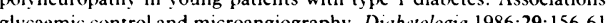

23 Dyball REJ, Tate PA. Basic embryology and the embryological basis of malformation syndromes. In: Robertson NEC, ed. Textbook of neonatology. malformation syndromes. In: Robertson NEC,

24 Sadler TW, Horton WE, Hunter ES. Mechanisms of diabetes-induced congenital malformations as studied in mammalian embryo culture. In: Jovanovic L, Peterson CM, Fuhrmann K, eds. Diabetes and pregnancy, teratology, toxicity and treatment. New York: Praeger, 1987:51-71.

25 Rayburn W, Piehl E, Jacober S. Severe hypoglycaemia during pregnancy, its frequency and predisposing factors in diabetic women. Int $\mathcal{G}$ Gynaecol Obstet 1986;24:263-8.

26 Bergman M, Seaton TB, Averhahn CC, et al. The incidence of gestational hypoglycemia in insulin-dependent and non-insulin dependent diabetic women. N Y State f Med 1986;86:174-7.
27 Bergman $M$, Newman S. Hypoglycemia in pregnancy, unknown risks. Diabetes Care 1987:10:180.

28 Mills JL, Knopp RH, Simpson JL, et al. Lack of relation of increased malformation rates in infants of diabetic mothers to glycemic control during organogenesis. N Engl f Med 1988;318:671-6.

29 Anonymous. Congenital abnormalities in infants of diabetic mothers [Editorial]. Lancet 1988;i:1313-5.

30 Fuhrmann K, Reiher H, Semmler K, et al. Prevention of congenital malformation in infants of insulin dependent diabetic mothers. Diabetes Care 1983;6:219-23.

31 Fuhrmann K, Reiher H, Semmler K, Glockner E. The effect of intensified conventional insulin therapy before and during pregnancy on the malformation rate in offspring of diabetic mothers. Exp Clin Endocrinol 1983;83: 173-7.

(Accepted 8 August 1990)

\title{
Ultrasonography compared with intravenous urography in the investigation of adults with haematuria
}

\author{
John Spencer, David Lindsell, Irene Mastorakou
}

\begin{abstract}
Objective-To compare ultrasonography with intravenous urography in the investigation of adults with haematuria.

Design-Prospective study entailing the examination of all patients with both investigations concurrently. The investigations were performed independently on routine lists by different duty radiologists. Each was aware of the details of the request form but not of the findings of the other investigation.
\end{abstract}

Setting-Radiology department of a teaching hospital.

Patients-155 Consecutive adult patients (aged 18-93) referred from general practitioners and hospital outpatient clinics with a history of haematuria.

Follow $u p-$ When results of both examinations proved normal no clinical or radiological follow up was sought. All abnormal findings of either investigation were correlated with results of subsequent imaging studies or operative findings.

Results -81 Patients (52\%) had normal findings on urography and ultrasonography. Overall, the findings of ultrasonography concurred with those of urography in 144 cases (93\%). Among the discrepant findings of the two investigations ultrasonography missed two ureteric calculi; one was in a non-dilated ureter, and in the other case ultrasonography detected the secondary ureteric dilatation. Ultrasound examination alone detected four bladder tumours not visible on urography with sizes ranging from 5 to $21 \mathrm{~mm}$, representing one fifth of the 20 cystoscopically proved bladder tumours detected in the series. Ultrasonography detected all the 22 neoplastic lesions discovered in the study (20 bladder, two renal). Ultrasonography clarified the nature of renal masses evident in three urograms (simple cysts).

Conclusions-Ultrasonography is a safe and accurate method of investigating the urinary tract in adults with haematuria. When combined with a single plain abdominal radiograph it proved to be superior to urography as the primary imaging study in this series. Ultrasonography should certainly be preferred to urography if cystoscopy is not planned. No urothelial tumours of the upper urinary tract were found in the series, reflecting their rarity. For those patients in whom ultrasonography and plain radiography have shown no abnormality and in whom cystoscopic appearances are normal urography would be advisable to exclude urothelial tumours of the upper urinary tract.

\section{Introduction}

It has been standard urological practice to request an intravenous urogram as the initial radiological investigation of patients with haematuria. In the light of improvements in newer imaging techniques the continued use of urography has been questioned. ${ }^{1}$ Ultrasonography can provide images of both the upper and lower urinary tract and is without the potential hazards of ionising radiation and intravenous contrast media. This technique supplemented by a single abdominal radiograph has supplanted urography in investigating certain urinary tract disorders, notably urinary tract infection in childhood, ${ }^{23}$ and a similar policy has been recommended for the investigation of adults with urinary tract infection. ${ }^{+}$Ultrasonography has also been shown to have advantages over urography in assessing prostatic disease. ${ }^{56}$ The efficacy of ultrasonography in the investigation of haematuria does not seem to have been assessed prospectively in a large group of adults. We therefore conducted a comparative study of the accuracy of ultrasonography and urography in patients with haematuria referred for urography from both general practice and hospital outpatient clinics.

\section{Patients and methods}

One hundred and fifty five consecutive patients (121 men, 34 women) referred from general practitioners and the hospital outpatient department with a history of haematuria and a request for intravenous urography were entered into the study. Their ages ranged from 18 to 93 years (mean 59.7), and most were referred from general practice. The clinical details provided on the request forms for some patients were very limited and did not indicate the type or severity of haematuria in all cases. We did not include patients with haematuria associated with a known urinary tract infection. These patients were entered into a separate prospective comparative trial. ${ }^{4}$ Patients with traumatic haematuria and those with acute ureteric colic were also excluded.

The patients were sent a routine appointment for intravenous urography with an explanation that an ultrasound examination would also be performed. In all cases the investigations were performed concurrently. The patients attended the hospital between October 1988 and January 1990. 